\title{
Associations between Student Achievement and Perceptions of Small Group Learning
}

\author{
Gabrielle O’Hara $^{1}$ and Tina Montreuil ${ }^{2}$ \\ McGill University Room 614, 3700 McTavish St., Montreal, QC, Canada H3A 1 Y2 \\ E-mail: ${ }^{1}<$ gabrielle.ohara@mail.mcgill.ca>, ${ }^{2}<$ tina.montreuil@mcgill.ca $>$
}

KEYWORDS Achievement. Collaborative Learning. Cooperative Learning. Pedagogy. Small Group Learning

\begin{abstract}
Existing research on small group learning with high-achieving students has been divided; although some researchers argue that this technique is detrimental to high-achievers, others endorse benefits for all learners. The current study aimed to assess whether academic achievement is associated with students' perspectives on small group learning. Forty-seven (47) children between the ages of 6-12 years participated in the study by answering questions pertaining to group learning. Students' academic achievement was assessed via their report card grades. A binomial logistic regression failed to find that academic achievement was predictive of the likelihood that students preferred working alone, however, a second binomial logistic regression discovered that higher achieving students were more likely to report that they learn better individually as opposed to in groups. This provides additional context for previous studies, by suggesting that perhaps it is not that high-achievers do not enjoy group work, but rather, they feel more confident in their individual abilities.
\end{abstract}

\section{INTRODUCTION}

For the last several decades, educational bodies and professional associations, such as the National Education Association (2017), have recommended that teachers make use of small group learning activities in their classrooms. Small group learning, which encompasses both "collaborative" and "cooperative" learning, allows children to work on problems, contribute ideas, and collaborate to accomplish shared goals in small peer groups (Cohen 1994; Gillies 2003). While most learning typically involves a student-teacher interaction, small group learning promotes interaction between students and involves working on tasks collaboratively (Webb 1982). Today, small group learning is considered a favored teaching strategy among both primary and secondary school teachers and is widely used from pre-school through to post-secondary (Johnson and Johnson 2002). When employed correctly, the benefits of small group learning include development of critical thinking skills, promotion of interpersonal relationships, consideration of alternative perspectives, and practice justifying viewpoints (Blumenfeld et al. 1996; Fuchs et al. 2002). Further, implementation of small group learning activities is viewed as a cornerstone of inclusive classrooms, as when properly implemented has been demonstrated to increase motivation and peer acceptance for learners of all abilities (Belland et al. 2009).

Although small group learning is a teaching style that is typically favoured by teachers and other stakeholders in the educational community, some previous studies have questioned its use with gifted and high-achieving students (Robinson 1990). As a technique, small group learning is highly variable in its effectiveness, given that positive outcomes can be negated by the nature of the learning task, the participants, and the amount of structure dictated by the teacher (Blumenfeld et al. 1996; Gillies 2003; Montreuil 2016; Webb 1982). Moreover, poorly organized small group learning activities may negatively impact classroom dynamics, leaving low-achieving students feeling isolated and stigmatized (Blumenfeld et al. 1996) and high-achieving students feeling over-burdened and exploited (Robinson 1990). As such, the purpose of this study was to elucidate the relationship between achievement and students' perceptions of small group learning, by differentiating between enjoyment and perception of performance in small group modality. Additionally, few recent studies have examined the relationship between achievement and perceptions of small group learning, thus the current study will provide an updated appraisal of the existing literature. 


\section{Small Group Learning}

Small group learning is a broad term that refers to a variety of teaching strategies which require two or more students to work together to complete tasks and/or learn new information. Among the strategies considered to be under the umbrella of small group learning are cooperative and collaborative learning. Although these terms are technically distinct, they are often used interchangeably by educators and researchers alike (Chinn 2010). Whilst both collaborative and cooperative learning share a common goal, to have students work interdependently in order to achieve a collective aim, they differ slightly in their implementation. While cooperative learning is ideally quite heavily structured by the teacher, such that each student has a specific role and the success of the group is dependent on each individual fulfilling that role, collaborative learning is less methodical and gives the students more independence in the way that they organize themselves (Bruffee 1995). Considering the current study includes the reactions of high-achieving students to any form of group learning, the term small group learning will be employed consistently throughout this paper to reflect the generality of the research question. The terms collaborative and cooperative learning may be used throughout the literature review in reference to previous works that specifically refer to either of these two teaching strategies.

Small group learning is an integral part of most modern-day classrooms (Johnson and Johnson 2009). Usually introduced in the early elementary school years, it often extends into high school, and even into post-secondary classrooms (Slavin 2015). Both researchers and school stakeholders agree that small group learning has positive effects on student achievement (Slavin 2015; Johnson and Johnson 2009). Even students themselves tend to report positively on their experiences working in small group modality, describing enjoyment and fulfillment as a result of their cooperation (Gillies 2003; Genc 2016).

Although students generally respond favourably to small group learning, research has indicated that both classroom characteristics and individual differences can impact students' perceptions and performance. Gillies (2003) under- scored the importance of classroom characteristics for successful group learning by comparing student performance and perceptions during "structured" and "unstructured" small group learning. The unstructured group was comprised of teachers who had received no training in smallgroup learning implementation, classrooms which only engaged in small group learning exercises periodically, and schools that did not include small group learning as part of their mandate. Alternatively, the structured group included classrooms that engaged in small group learning at least once a week, and involved teacherassigned tasks that necessitated group involvement. Students in the structured group reported more positively on their learning experience, and described the group work as being more enjoyable in comparison to the students in the unstructured group. Furthermore, students in the structured group were more likely to work collectively on the task and demonstrate helping behaviours.

Other studies have supported Gillies’ (2003) assertion that situational factors, such as classroom and task structure, are integral to the successful implementation of small group learning. For instance, Blumenfeld et al. (1996) stated that the effects of small group learning depend on the organization of groups and the structure of the task, and further, that uninformed implementation of cooperative and collaborative learning can lead to dysfunctional interactions among students and an exacerbation of existing status differences. Similarly, Gillies and Ashman (1998) discovered that when students were given instruction on how to engage with their peers during small group learning, they were more likely to have positive interactions, such as listening, information sharing, and turn taking. Furthermore, the same students demonstrated more effective collaboration and commitment to the group task than those with no prior instruction.

\section{Small Group Learning with High-achievers}

Despite these generally favourable assessments of small group learning, the use of this particular technique with gifted and high-achieving students remains hotly debated. While certain studies have found that high-achieving students are less likely to report positively on their experiences working and learning in small groups (Matthews 1992) and may be more suit-

Int J Edu Sci, 25(1-3): 1-7 (2019) 
ed to other instructional formats ( $\mathrm{Li}$ and Adamson 1992), others have maintained that small group learning benefits learners of all abilities, and have found that high-achievers reap many of the same advantages as other students (Johnson et al. 1993).

Robinson (1990) for one argues that the use of cooperative learning as a dominant instructional strategy precludes high-achievers from learning new information, and instead simply reinforces the knowledge they already possess. Specifically, she suggests that instruction cannot be individualized to meet the needs of highachieving students when these students are placed in groups with students whose level of knowledge and understanding is not as advanced as their own. Further, Robinson (1990) asserts, based on previous researchers' conceptualizations of cooperative learning (Webb 1982), that small groups are in fact exploitative of highachievers, as other group members rely on their expertise, which leaves them feeling responsible for the success of the group. One study assessed the learning preference of gifted secondary students and found that cooperative learning was not the preferred style of learning in any subject. In fact, when asked to rate their learning preferences gifted students endorsed a marked preference for individualistic or competitive learning styles, when compared to cooperative learning styles ( $\mathrm{Li}$ and Adamson 1992). Moreover, previous studies have emphasized the importance of emotions in determining students' level of engagement during cooperative learning (Linnenbrink-Garcia et al. 2011), thus providing support for the contention that a baseline level of enjoyment may be integral to performance in small group learning.

Although it was previously taken for granted that higher-achieving students preferred to work and learn individually as opposed to in groups (Neber et al. 2001), more recent studies have disputed this assertion, and argued that the circumstances of the small group task influence the opinions of high-achievers (French et al. 2011). For instance, high-achievers tend to report negatively on small group learning when it occurs in unstructured mixed-ability groups, and particularly when they feel as though they've taken on the role of tutor (Matthews 1992; Robinson 1990), however, they report a preference for small group learning when the task has low stakes and the group is made up of esteemed peers (Walker and Shore 2015). This suggests that the nature of the task plays an important role in student's perceptions, and that the issue of employing small group learning with high-achieving students may be more nuanced than previously thought.

Other studies have demonstrated that highachieving students experience the same cognitive benefits during small group learning as their peers, for instance, improved recall and highlevel reasoning (Johnson et al. 1993). Moreover, researchers suggest that when group tasks involve higher-order reasoning, and students are encouraged to give thorough explanations and justify their positions, high-achieving students can in fact benefit from mixed ability groups (Patrick et al. 2005). Further, to the benefit of all students, frequent classroom implementation of small group learning has been posited to decrease bullying by increasing students' prosocial behaviour, and reducing individualistic predispositions (Choi et al. 2011).

\section{Objectives}

Together, this suggests that small group learning has variable results and is subject to changes in efficacy based on a variety of individual and situational circumstances. It remains unclear whether small group learning is preferred or spurned among high-achievers, as various respected researchers in the field of education have continued to disagree on this topic. As such, the objective of the current study was to further assess whether academic achievement is associated with student's learning preferences. What differentiates this study from previous studies examining small group learning in the context of academic achievement is the differentiation made between a preference for working in groups, and an assessment of how well one learns in groups. The purpose of this distinction was to gain a better understanding the nuances present in the relationship between academic achievement and small group learning, in order to better address the concerns of high-achieving students in the future. The current study aimed to answer two research questions:

1) Does academic achievement predict the likelihood that students will prefer to work alone as opposed to in groups?

Int J Edu Sci, 25(1-3): 1-7 (2019) 
2) Does academic achievement predict the likelihood that students will report learning better alone as opposed to in groups?

\section{MATERIAL AND METHODS}

\section{Participants}

Fifty-four (54) children between the ages of 6-12 years were recruited as part of a larger intervention study, which examined the efficacy of a classroom-based manualized emotion-regulation and mindfulness program, from a bilingual Montreal elementary school. Seven (7) participants were excluded prior to analysis, due to missing data pertaining to academic achievement, resulting in a total of 47 participants. The mean age of participants was $8.66(S D=1.86)$. There were 29 participants who identified as male, and 18 who identified as female. Participants were from eight different classrooms, which ranged from grades one through six.

\section{Material}

Participants were asked to answer two forcedchoice questions about their small group learning preferences. The first question asked participants to indicate whether they "[preferred] to work by themselves or with classmates when in school?". The second question asked participants "if you were being asked to learn something new, do you think you would learn it better alone or by going over it with your classmates?". These questions were purposefully designed using simple language so that young participants could easily understand what they were being asked. Children's final grades as reported on their midterm report cards were used as a measure of their academic achievement. A total academic achievement score was obtained by calculating the mean of the language arts and mathematics grades.

\section{Procedure}

Trained facilitators entered the participants' classrooms and assisted the children in understanding and duly completing the questionnaires. Facilitators took groups of three to four students at a time and verbally went through the questionnaires item by item, to ensure that each student understood the questions and provided accurate responses. Data for this project was collected as part of a larger intervention study, and thus, participants were randomly assigned by classroom to either an intervention or wait-list control condition group. The data used in this project was collected during pre-test (held in February 2018) from both experimental and control conditions. This study was approved by the McGill Research Ethics Board. Teachers consented to have their classrooms partake in the intervention, which was integrated into the curriculum. Parents provided written consent for their children to participate in data collection, and children provided oral and written assent prior to completing the questionnaires.

\section{RESULTS}

Data was analyzed using SPSS Statistics. Two binomial logistic regressions with 10,000 bootstrapped samples were performed in order to ascertain the predictive value of academic achievement $(M=78.07, S D=8.47)$ on the likelihood that students reported a preference for small group learning, based on the two questions listed above. Frequencies for both small group learning questions are located in Table 1. This method of statistical analysis was chosen for two reasons. First, the dependent variables were dichotomous, which limited the number of statistical methods available to properly address the research questions. Further, logistic regression requires a sample size of 15 cases per independent variable, making it suitable for the relatively small number of cases included in this study (Laerd Statistics 2015). Linearity of the continuous variable with respect to the logits of the dependent variables were assessed via two Box-Tidwell (Box and Tidwell 1962) procedures, and the assumption of linearity was met in both cases. An examination of the standardized residuals revealed no outliers, such that no residual values exceeded 2.5. No assumptions were violated.

Table 1: Frequencies for self-report of working and learning preferences

\begin{tabular}{lcc}
\hline & Alone & With others \\
\hline Working preference & 18 & 29 \\
Learning preference & 15 & 32 \\
\hline
\end{tabular}

Int J Edu Sci, 25(1-3): 1-7 (2019) 
The first logistic regression assessed whether academic achievement predicted the likelihood that students preferred to do schoolwork alone, as opposed to in groups. A Hosmer-Lemeshow test was carried out to assess the goodness of fit of the model, and the predicted probabilities were found to match the observed probabilities, $\chi^{2}(7)=63.58, p=.83$. This model was not statistically significant, nor was the effect of academic achievement on working preference significant when bootstrapping was applied. As such, academic achievement was not significantly associated with a preference for individual or group work. A second logistic regression was carried out in order to assess whether academic achievement would predict the likelihood that students reported learning better individually as opposed to in groups. A Hosmer-Lemeshow test was carried out to assess the goodness of fit of the model, and the predicted probabilities were found to match the observed probabilities, $\chi^{2}(7)=3.65$, $p=.82$. The logistic regression model was statistically significant, $\chi^{2}(1)=4.35, p<.05$ and accounted for 10.70 percent of the variance in learning preference, Nagelkerke $R^{2}=10.7$. The model correctly classified 65.20 percent of cases. When applying bootstrapping, the predictive value of achievement on students' belief that they learn better alone was significant, $B=-.09, S E=.05$, $p<.05,95 \%$ CI [-.20;-.02].

\section{DISCUSSION}

Small group learning is a staple of North American classrooms and boasts impressive results for students, including increases in motivation and peer acceptance (Belland et al. 2009). Previous studies examining small group learning with high-achieving and gifted students have thus far yielded mixed results. For instance, while Robinson (1990) suggests that when gifted and high-achieving students engage in small group learning they are disadvantaged because the difficulty of the subject matter must be limited to the ability of the group, Patrick et al. (2005) suggest that when used appropriately, small group learning can promote deeper understanding of the subject matter for high and low achieving students, alike. Further, regular integration of group learning into the classroom may in fact result in greater appreciation and enjoyment of the subject overall (Smith 2014). Other studies specifically examining high-achieving and gifted students' perceptions of small group learning have likewise come to differing conclusions. $\mathrm{Li}$ and Adamson (1992) found that high-achievers preferred individualistic and competitive learning styles as opposed to cooperative, yet French et al. (2011) found that gifted students respond differently to small group learning depending on several factors, including the way in which the question is posed. As such the aim of this study was to shed further light on this topic by differentiating between students' preferences for working in groups and their assessment of whether they learn better in groups or individually.

Although higher achievement was not predictive of an increased likelihood of preferring individual work, results from the current study suggest that when asked directly high-achieving students were more likely to report learning better individually as opposed to in groups. Previous studies have failed to take a nuanced approach in their examination of high-achievers' responses to small group learning, despite researchers noting that context is critical when examining this particular phenomenon (French et al. 2011). This is the first study to make a clear distinction between enjoyment of small group learning and self-assessment of the ability to learn in group versus individual learning modalities. Differentiating between these two distinct dimensions further elucidates the results of many previous studies, which have uncovered that high-achievers respond negatively when asked about their experiences in small group learning. The current study supports the contention that a more nuanced view is required, such that students differed in their responses on the two items, indicating that simply asking students how they would prefer to learn is not sufficient. As the current study suggests, this may be a difficult question for students to answer, as although they may feel enjoyment when working in small groups with their peers, they might feel as though this comes at the cost of their performance. In fact, this particular finding provides some support to Robinson's (1990) claim that high-achieving students are unable to exercise their full potential during small group learning, as the researchers' findings seem to suggest that high-achieving students themselves endorse a similar assertion.

Int J Edu Sci, 25(1-3): 1-7 (2019) 
Although numerous studies have claimed that small group learning is beneficial for all students, underachieving and overachieving alike, high-achieving and gifted students themselves have repeatedly disputed these findings, as several qualitative studies have found (Matthews 1992; French et al. 2011). The current study provides some support for the notion that the benefits of small group learning may be limited when it comes to high-achievers. Nonetheless, despite feeling as though they are more suited to individual learning modalities, several studies have demonstrated that high-performing students benefit both socially and academically from small group learning (Neber et al. 2001). As such, future efforts should endeavor to improve highachieving students' perspectives on small group learning, so that they may fully benefit from this pedagogical method.

\section{CONCLUSION}

In summary, the current study contributed to the existing literature by replicating previous findings from several studies. Results from this study failed to support the notion that highachieving students are more likely to favour direct instruction and individual work, as opposed to small group learning, however, it was demonstrated that high-achieving students report that they learn better individually, as opposed to in groups. This sheds further light on a topic that has yielded mixed results in the existing research. Specifically, results from this study suggest that high-achievers may in fact enjoy working in groups, but nonetheless feel they are better able to demonstrate their abilities individually.

\section{LIMITATIONS}

The present study had several limitations which may affect the generalizability of the findings. First, the initial sample size was relatively small $(N=54)$ and several cases had to be eliminated throughout the analysis due to missing data, which further minimized the sample size and thus the power of the analyses. Further, all participants were from a single school, and thus findings of this particular study may not generalize well, given the differences in operational and instructional style that exist between schools.

Although this study was interested in measuring student's perceptions of cooperative learning, it should be acknowledged that perception does not necessarily translate into performance. Although high-achieving students may have reported that they learn better individually, this may not manifest as a decrease in performance.

Both the current study and previous studies have failed to adequately control for the manner in which small group learning is carried out at the school level, thereby making it difficult to assess whether instructional trends are affecting students' perceptions.

\section{RECOMMENDATIONS}

Future researchers should collect data from several schools, in order to create a more diverse sample and control for school-wide policies relating to small group learning. It would be beneficial to impose a school-wide measurement to assess how small group learning is carried out in each classroom, in order to better isolate variables at the individual student level. Further, future studies examining achievement and small group learning should make use of objective measures, such as direct observation, in order to assess children's performance and participation, as this may yield different results than self-report data.

With regard to practical recommendations, results from this study and prior studies suggest that teachers should take a structured approach when implementing small group learning in the classroom with high-achieving students in order to reduce their perception that this modality will be detrimental to their performance. For instance, teachers should ensure each student has a specific role and set expectations for individual students as well as the group as a whole.

\section{REFERENCES}

Belland BR, Glazewski KD, Ertmer PA 2009. Inclusion and problem-based learning: Roles of students in a mixed-ability group. Research in Middle Level Education, 32: 1-19. DOI: 10.1080/19404476. 2009. 11462062 .

Int J Edu Sci, 25(1-3): 1-7 (2019) 
Blumenfeld PC, Marx RW, Soloway E, Krajcik J 1996. Learning with peers: From small group cooperation to collaborative communities. Educational Researcher, 25: 37-40. DOI: 10.2307/1176492.

Box GEP, Tidwell PW 1962. Transformation of the independent variables. Technometrics, 4: 531-550. DOI: $10.1080 / 00401706.1962 .10490038$.

Bruffee KA 1995. Sharing our toys: Cooperative learning versus collaborative learning. Change: The Magazine of Higher Learning, 27: 12-18. DOI: 1080/ 00091383.1995 .9937722$.

Chinn C 2010. Cooperative and collaborative learning. In: CS Clauss-Ehlers (Ed.): Encyclopedia of Crosscultural School Psychology. Boston, MA: Springer, pp. 229-232.

Choi J, Johnson DW, Johnson R 2011. Relationships among cooperative learning experiences, social interdependence, children's aggression, victimization, and prosocial behaviors. Journal of Applied Social Psychology, 41: 976-1003. DOI: 10.1111/j.15591816.2011.00744.x.

Cohen E 1994. Restructuring the classroom: Conditions for productive small groups. Review of Educational Research, 64: 1-35. DOI: 10.3102/003465 43064001001.

French LR, Walker CL, Shore BM 2011. Do gifted students really prefer to work alone? Roeper Review, 33: 145-159. DOI: 10.1080/02783193. 2011.580497.

Fuchs LS, Fuchs D, Yazdian L, Powell SR 2002. Enhancing first-grade children's mathematical development with peer-assisted learning strategies. School Psychology Review, 31: 569-583.

Genc M 2016. An evaluation of the cooperative learning process by sixth grade students. Research in Education, 95: 19-32. DOI: 10.7227/RIE.0018.

Gillies RM 2003. The behaviors, interactions, and perceptions of junior high school students during small group learning. Journal of Educational Psychology, 95: 137-147. DOI: 10.1037/0022-0663.95.1.137.

Gillies RM, Ashman AF 1998. Behavior and interactions of children in cooperative groups in lower and middle elementary grades. Journal of Educational Psychology, 90: 746-757. DOI: 10.1037/00220663.90.4.746.

Johnson DW, Johnson RT 2002. Cooperative learning and social interdependence theory. In: RS Tindale, L Heath, J Edwards et al. (Eds.): Theory and Research on Small Groups. US: Springer, pp. 9-35.

Johnson DW, Johnson RT 2009. An educational psychology success story: Social interdependence theory and cooperative learning. Educational Researcher, 38: 365-379. DOI: 10.3102/0013189X09 339057.

Johnson DW, Johnson RT, Taylor B 1993. Impact of cooperative and individualistic learning on high-abili- ty students' achievement, self-esteem, and social acceptance. The Journal of Social Psychology, 133: 839-844

Laerd Statistics 2015. Binomial Logisticx Regression Using SPSS Statistics. Statistical Tutorials And Software Guides. From <https://statistics.laerd.com/> (Retrieved on 24 May 2019).

Li AKF, Adamson G 1992. Gifted secondary students preferred learning style: Cooperative, competitive, or individualistic? Journal for the Education of the Gifted, 16: 46-54.

Linnenbrink-Garcia L, Rogat TK, Koskey KLK 2011. Affect and engagement during small group instruction. Contemporary Educational Psychology, 36: 13-24. DOI: 10.1016/j.cedpsych.2010.09.001.

Matthews M 1992. Gifted students talk about cooperative learning. Educational Leadership, 50: 48-50.

Montreuil T 2016. Social Anxiety: Implications for Group Learning. The ABCT Child and SchoolRelated Issues Special Interest Group. Fall Newsletter.

National Education Association 2017. Research Spotlight on Best Practices in Education: An NEA Venue for Best Pedagogical Practices. From <http://www. nea.org/tools/17073.htm> (Retrieved on 5 June 2018).

Neber H, Finsterwald M, Urban N 2001. Cooperative learning with gifted and high-achieving students: A review and meta-analysis of 12 studies. High Ability Studies, 12: 199-214. DOI: 10.1080/1359813012 0084339.

Patrick H, Bangel NJ, Jeon K, Townsend MAR 2005. Reconsidering the issue of cooperative learning with gifted students. Journal for the Education of the Gifted, 29: 90-108. DOI: 10.1177/01623532050 2900105.

Robinson A 1990. Cooperation or exploitation? The argument against cooperative learning for talented students. Journal for the Education of the Gifted, 14: 927.

Slavin RE 2015. Cooperative learning in elementary schools. International Journal of Primary, Elementary, and Early Years Education, 43: 5-14. DOI: 10.1080/03004279.2015.963370.

Smith TJ 2014. Association of group learning with mathematics achievement and mathematics attitude among eighth-grade students in the US. Learning Environment Research, 17: 229-241. DOI: $10.1007 /$ s10984-013-9159-x.

Walker CL, Shore BM 2015. Myth busting: Do high performing students prefer working alone? Gifted and Talented International, 30: 85-105. DOI: 10.1080/15332276.2015.1137461.

Webb NM 1982. Student interaction and learning in small groups. Review of Educational Research, 52: 421-445. DOI: 10.3102/00346543052003421.

Paper received for publication in March, 2019

Paper accepted for publication in April, 2019

Int J Edu Sci, 25(1-3): 1-7 (2019) 